This item was submitted to Loughborough's Research Repository by the author.

Items in Figshare are protected by copyright, with all rights reserved, unless otherwise indicated.

\title{
Preparation and characterization of high performance exfoliated montmorillonite/silicone rubber nanocomposites with enhanced mechanical properties
}

\section{PLEASE CITE THE PUBLISHED VERSION}

http://dx.doi.org/10.1002/pen.23528

\section{PUBLISHER}

Wiley (@ Society of Plastics Engineers)

\section{VERSION}

AM (Accepted Manuscript)

\section{PUBLISHER STATEMENT}

This work is made available according to the conditions of the Creative Commons Attribution-NonCommercialNoDerivatives 4.0 International (CC BY-NC-ND 4.0) licence. Full details of this licence are available at: https://creativecommons.org/licenses/by-nc-nd/4.0/

\section{LICENCE}

CC BY-NC-ND 4.0

\section{REPOSITORY RECORD}

Ismail, Nik I. Nik, Ali Ansarifar, and Mo Song. 2017. "Preparation and Characterization of High Performance Exfoliated Montmorillonite/silicone Rubber Nanocomposites with Enhanced Mechanical Properties". figshare. https://hdl.handle.net/2134/23765. 
Preparation and Characterization of High Performance Exfoliated

Montmorillonite/Silicone Rubber Nanocomposites with Enhanced Mechanical

Properties

N I Nik Ismail*, A Ansarifar and M Song

Materials Department, Loughborough University, Leicestershire LE11 3TU, UK

Correspondence to: $\underline{\text { N.I.B.Nik-Ismail@lboro.ac.uk }}$

Tel: +44 (0) 01509223159

Fax: +44 (0) 01509223949 


\section{Preparation and Characterization of High Performance Exfoliated \\ Montmorillonite/Silicone Rubber Nanocomposites with Enhanced Mechanical}

\section{Properties}

\section{N I Nik Ismail, A Ansarifar and M Song}

Department of Materials, Loughborough University,

\section{Loughborough, Leicestershire, LE11 3TU, United Kingdom}

Highly exfoliated and intercalated silicone rubber (SR) nanocomposites based on natural montmorillonite (Cloisite $\mathrm{Na}^{+}$) and organically modified montmorillonite (Cloisite 30B and Cloisite 20A) were successfully prepared by melt-mixing technique. Dispersion of the nanoclays in the rubber nanocomposites was subsequently investigated. As indicated by the X-ray diffraction (XRD) analysis, intercalation and exfoliation of the clay particles in the nanocomposites was achieved at less than 8 parts per hundred (phr) rubber by weight, irrespective of the initial interlayer spacing of the nanoclay particles. Both Cloisite $\mathrm{Na}^{+}$and Cloisite 30B were spontaneously transformed into exfoliated microstructures during the vulcanisation stage. Overall, the use of the nanoclays in silicone rubber improved the Young's modulus, tensile strength and elongation at break by more than $50 \%$ as compared to the control rubber. In addition, this work provided a fresh insight into the way intercalated and exfoliated morphologies affect mechanical properties of silicone rubber nanocomposites. 
It was shown that the exfoliated Cloisite $\mathrm{Na}^{+}$yielded outstanding mechanical properties with low hysteresis at the same loading of the exfoliated Cloisite $30 \mathrm{~B}$ and intercalated Cloisite 20A organoclays. As expected, the formation of crosslinks affected the mechanical properties of the rubber vulcanizate significantly.

KEY WORDS: rubber, clay, compounding, crosslinking, X-ray .

\section{INTRODUCTION}

Silicone rubber is an important elastomer in the rubber industry, since it is widely used

to manufacture industrial products such as cables, gaskets, sealants, and bio-implants because

of its excellent resistance to ultraviolet, ozone, oxygen and chemicals, and good electrical properties and physiological inertness. However, SR has poor mechanical properties in particular low tensile strength. Hence, reinforcing fillers such as fumed and precipitated silicas are used frequently to improve mechanical properties and this offers excellent benefits to the rubber.

More recently, research has begun to investigate a new filler system for silicone rubber due to the high price of silica and also the occurrence of silicosis condition among users of silica such as rubber compounders. Therefore, a number of potential fillers for example nanoclay [1-8], titanium oxide [9], and carbon nanotube [10, 11] have been used in 
silicone rubber. Among the fillers, nanoclay or montmorillonite (MMT) has received much attention in recent years because it is relatively inexpensive and also non-carcinogenic. In addition, according to some previous studies MMT filler imparts outstanding mechanical properties at very low loading of the filler, i.e. $<10 \mathrm{wt} \%$, to most clay/rubber nanocomposites [12-14]. Recent studies have shown that layered silicates offer significant improvement to the thermal [15] and barrier properties [16] of rubber nanocomposites.

Since MMT consists of a triple-layer sandwich structure, therefore its dispersion mechanism in rubber is different from silica that has a spherical shape [13]. As reported in the literature [13-17] intercalation and exfoliation morphologies are used to characterize the clay layer dispersion in clay/polymer nanocomposites. The latter morphology is more desirable due to its high surface area, which is important in rubber reinforcement. Nevertheless, producing a high level of clay dispersion in silicone rubbers such as polydimethylsiloxane is a challenge because of the dual nature of the rubber which is made of inorganic (Si-O-Si) and organic methyl groups $\left(\mathrm{CH}_{3}\right)$, respectively. For this reason, lots of work has been carried out to examine ways to incorporate layered silicates into silicone rubber. A variety of techniques to prepare clay/silicone rubber nanocomposites have been discussed in detail in numerous papers [15-17]. 
Horsch and co-workers [17] modified nanoclays with supercritical carbon dioxide $\left(\mathrm{CO}_{2}\right)$ and used this technique to produce high $\mathrm{scCO}_{2}$ dispersed clay in polydimethylsiloxane (PDMS) polymer. This method was chosen because PDMS and $\mathrm{scCO}_{2}$ had good miscibility which helped with the processing of $\mathrm{scCO}_{2}$ with the rubber. A series of commercial organoclays (Cloisite 93A, Cloisite 15A and 1.30P) and natural clays (Cloisite $\mathrm{Na}^{+}$) were successfully exfoliated in silicone rubber matrix with this method, but the level of dispersion varied depending on the $\mathrm{CO}_{2}$-philicity of the nanoclay. The nanocomposite-based $\mathrm{CO}_{2^{-}}$ phobic Cloisite $\mathrm{Na}^{+}$, and $\mathrm{CO}_{2}$-philic polydimethylsiloxane appeared to be the best combination that demonstrated a high level of dispersion and this lead to a significant enhancement in the rheological properties of the rubber.

Simon and co-workers [18] produced grafted siloxane modified montmorillonite to enhance its compatibility with siloxane chains in liquid silicone rubber (LSR). The siloxane modified montmorillonite was easily exfoliated in the LSR and contributed to $20 \%$ reduction in water vapour permeation. Though, no improvement in the tensile strength was reported for this grade of silicone rubber [18]. Bhowmick and Roy [19] proposed an in situ polymerisation technique to produce high dispersion of PDMS-sepiolite nanocomposite. Excellent clay dispersion and high interaction between clay and PDMS was observed in the 
nanocomposites produced from this technique with respect to ex situ prepared nanocomposite. This produced significant enhancement in the mechanical and thermal properties of the rubber.

Although the techniques reported above were useful, they involved a complex process which was less suitable for practical industrial applications which require simple and cost effective ways to produce rubber compounds. In this study, a simple and versatile meltmixing route using a small laboratory internal mixer was utilised to produce clay/rubber nanocomposites. It must be noted that there are a few literatures which report the use of meltmixing technique to disperse clay particles in clay/silicone rubber nanocomposite [3-6]. In addition, to the best of our knowledge, the fundamental process that contributes to the exfoliation process in silicone rubber is not well understood.

Kaneko and Yoshida [3] claimed that due to the low viscosity of silicone rubber, it was hard to obtain sufficient mechanical shearing forces during melt-mixing to produce intercalation of the SR chains into the interlayer spacing of organoclay (OMMT). For this reason, poor dispersion of the clay layers and small amounts of the filler in the rubber caused the poor mechanical performance of the SR/clay nanocomposites. Subsequent studies emphasized the need to improve processability of the melt-mixed SR/clay nanocomposites 
[6]. It was suggested that the viscosity of silicone rubber could improve by the addition of up to $30 \mathrm{phr}$ filler loading [6]. Nevertheless, with increasing the clay loading the chances of the filler particles re-agglomerating was high and this led to poor mechanical properties.

This work was carried out to investigate dispersion of different clays in silicone rubber using the melt-mixing technique. Clay/SR nancomposites were prepared and cured and then the interlayer spacing, $d$, of the clay particles in the rubber matrix was measured by X-ray diffraction spectroscopy. Effect of the filler loading on the processing and mechanical properties of the rubber vulcanizate was investigated. In addition, the formation of exfoliated and intercalated structures in the clay/SR nanocomposites was discussed and effect of the clays on the cure characteristics and mechanical properties of the rubbers was measured. For a better understanding of the reinforcing mechanism of the clays, fresh insight into the way intercalated and exfoliated morphologies change the mechanical properties of the rubber nanocomposites was also discussed.

\section{EXPERIMENTAL}

\section{Materials}

The raw elastomer used was polydimethyl siloxane Silastic (R) SGM-26 with a molecular weight of 300,000 . It was a random copolymer in which some of the methyl 
groups were substituted with vinyl ones producing vinyl dimethyl silicone rubber. The end groups were vinyl siloxane. The vinyl content was $0.12 \mathrm{wt} \%$ (Dow Corning Limited, UK). A high purity (99\%) dicumyl peroxide (DCP) or bis( $\alpha, \alpha$-dimethylbenzyl) was used as a vulcanizing agent ( Fisher Scientific, UK). In addition, commercial Cloisite 30B and Cloisite 20A organoclays were also used, which were modified with different functional treatments namely methyl, tallow, bis-2-hydroxyetyl, quaternary ammonium (MT2EtOH), and dimethyl, dehydrogenated tallow, quaternary ammonium (2M2HT), respectively. The pristine montmorillonite was Cloisite $\mathrm{Na}^{+}$. Both unmodified clay and modified clays were supplied by Southern Clay Product, USA.

\section{Preparation of clay/SR nanocomposites}

Three rubber compounds were made: one was based on the natural clay and the other two based on the organoclays. An unfilled silicone rubber compound was also prepared as a control compound by mixing the raw rubber with peroxide (Table 1). Prior to mixing, the clays were dried in a vacuum oven at $60{ }^{\circ} \mathrm{C}$ for 48 hours to remove moisture. The silicone rubber and all the compounding ingredients were then mixed in a Polylab mixer OS (ThermoHAAKE, Germany) using counter-rotating Banbury rotors. The temperature of the mixing chamber and the rotor speed were set at $20{ }^{\circ} \mathrm{C}$ and 50 r.p.m., respectively, and the 
mixing time was 15 minutes. An oscillating disc rheometer (ODR) (Monsanto, Swindon, UK)

was used to measure the cure properties of the rubber compounds at $160{ }^{\circ} \mathrm{C}$. The rubber compounds were subsequently cured in a compression mould at $160{ }^{\circ} \mathrm{C}$ to produce sheets about $2 \mathrm{~mm}$ thick for further work.

\section{Characterization and measurement of the dispersion of the fillers in the rubber}

The X-ray diffraction (XRD) spectra of the layered silicates and clay-filled nanocomposites were produced on a Bruker D8 diffractometer (Bruker, Germany). The diffractometer was equipped with $\mathrm{Cu} K \alpha$ radiation $(\lambda=0.15418 \mathrm{~nm}), 40 \mathrm{~mA}$ of current and 40 $\mathbf{k V}$ of voltage. A minimum of $3 \mathrm{~g}$ of dried clay powder was used to carry out the X-ray analysis of the mineral clays. A square flat sheet $30 \mathrm{~mm}$ by $30 \mathrm{~mm}$ in dimensions and $2 \mathrm{~mm}$ thick of the cured compound was required for the X-ray analysis of the silicone rubber nanocomposites. The experiment was performed at a low angle in the range $2 \theta=1-10^{\circ}$ with the scan rate of $0.02 \%$ second. In addition, the spacing between the structural layers of the silicates was measured according to the Bragg's law (equation 1), where $n$ is an integer, $\lambda$ is the X-ray wavelength, $d$ is the interlayer spacing, and $\theta$ is the angle of diffraction.

$$
\lambda \mathrm{n}=2 \mathrm{~d} \sin \theta
$$


The heat of fusion of clay/SR nanocomposites was obtained with a differential scanning calorimeter (DSC) model 2920 (TA Instrument, USA). The test was performed from $50{ }^{\circ} \mathrm{C}$ to $220{ }^{\circ} \mathrm{C}$ at a heating rate of $10{ }^{\circ} \mathrm{C} \mathrm{min}^{-1}$. Furthermore, the clay dispersion was observed in a DMRX transmitted light microscope (Leica, Germany) using bright field technique. The tensile stress and elongation at break of the nanocomposites were measured in uniaxial tension in a Lloyd testing machine LR50K (Hampshire, UK) with standard dumbbell test pieces at $24{ }^{\circ} \mathrm{C}$ and a cross-head speed of $100 \mathrm{~mm} / \mathrm{min}$ according to BS903: Part A2;1995. Lloyd Nexygen 4.5.1 computer software was used to store and process the data. Five test pieces were tested for each compound and the median of the values was subsequently noted.

Finally, some stress-strain curves were produced for each rubber sample to determine the Young's modulus and store energy density at break. The store energy density at break was calculated from the area under the stress-strain curve using the trapezium rule. In each test, 10 stress-strain curves were generated. The strain amplitude on the rubber samples was set at $100 \%, 200 \%$ and $400 \%$, which corresponded to $25 \mathrm{~mm}, 50 \mathrm{~mm}$ and $100 \mathrm{~mm}$ extension of the gauge length. The energy dissipated in the rubber was calculated from the hysteresis loop, which was the area between the extension and retraction curves in each cycle. The 
hardness was measured in a Shore A Durometer hardness tester (The Shore Instrument and MFG, Co., New York) at $24{ }^{\circ} \mathrm{C}$ according to BS903: PartA26;1995. Finally, the median of the hardness values was noted.

\section{RESULTS AND DISCUSSIONS}

Effect of the filler loading on the dispersion of MMT in the rubber

Initially, dispersion of the fillers in the rubber nanocomposites was studied as a function

of the clay concentration. The rubber samples were prepared at clay loadings 4-12 phr and dispersion of the fillers was determined by XRD. In principle, a small amount of clay, i.e. 4 phr is sufficient to reveal the crystalline structure of the layered silicate in the rubber. Figs. 1(a-c) show the XRD spectra of Cloisite $\mathrm{Na}^{+}$, Cloisite 30B and Cloisite 20A dispersed in the rubber. According to the Bragg's law (Equation 1), the initial interlayer spacing $\left(\mathrm{d}_{001}\right)$ of the Cloisite $\mathrm{Na}^{+}$, Cloisite $30 \mathrm{~B}$ and Cloisite $20 \mathrm{~A}$ were $1.22 \mathrm{~nm}, 1.88 \mathrm{~nm}$ and $2.57 \mathrm{~nm}$, respectively. The larger $d$ spacings of Cloisite 30B and Cloisite 20A were expected because these fillers were modified with various organic surfactants. The modification was done to expand the interlayer spacing between the platelets and at the same time, reduce the surface energy of the platelet surfaces for improved compatibility with the polymer chains. 
Notably, the distinct diffraction peak observed for the pure Cloisite $\mathrm{Na}^{+}$at $2 \theta=7.23^{\circ}$

was absent in the spectra of the nancomposites containing 4-8 phr Cloisite $\mathrm{Na}^{+}$(Fig. 1a). The absence of the peak suggested that a highly exfoliated morphology had been achieved at these levels of the filler concentration. This was because XRD could not measure the irregular spacing of the platelets when exfoliation took place. Note that the limitation of the wide angle X-ray scattering detection is greater than $8 \mathrm{~nm}$ [14]. However, when the clay concentration increased to $10 \mathrm{phr}$ and $12 \mathrm{phr}$, small peaks appeared at $2 \theta=7.00^{\circ}$ to $7.05^{\circ}$. Since, the intensity of the peaks was very low, it was concluded that the nanoclay particles were partially exfoliated in the rubber.

Similarly, as shown in Fig. 1b, the flat spectra of the Cloisite 30B/SR nanocomposites containing up to $8 \mathrm{phr}$ of the clay, implied that exfoliation had occurred. However, when the loading of the clay exceeded $8 \mathrm{phr}$, broad reflection peaks were seen at the similar positions as the pure Cloisite 30B. This indicated that the clay particles did not exfoliate. Furthermore, a series of XRD spectra of the SR nanocomposites containing different loadings of the Cloisite 20A were also present in Fig. 1c. Evidently, the diffraction peaks of all the rubber nanocomposites containing up to $12 \mathrm{phr}$ of the filler shifted towards the lower angle in comparison with the original peak of the pure Cloisite 20A. According to the Bragg's law, 
the peak shift indicated that the gallery had stretched from its original size spacing. As reported in the literature, the increase in the interlayer spacing was caused by the insertion of the rubber chains into the silicate gallery, leading to the expansion of the interlayer spacing $[14,20]$.

Table 2 summarizes the peak positions of the Cloisite 20A/SR nanocomposites with different filler loadings and the $d$ spacing of the original Cloisite 20A. It seemed that the interlayer spacing of Cloisite 20A/SR nanocomposites depended on the clay concentration. The $d$ spacing $\left(\mathrm{d}_{001}\right)$ expanded to about $0.89 \mathrm{~nm}$ in the nanocomposites containing $4 \mathrm{phr}$ and 6 phr of Cloisite 20A. This indicated a highly intercalated structure. As the Cloisite 20A content reached $8 \mathrm{phr}$, the $\Delta d$ spacing started to decrease to the initial size. This phenomenon obviously can be seen at $10 \mathrm{phr}$ and $12 \mathrm{phr}$ of the filler loading. It was concluded that when a large amount of Cloisite 20A was presented in the rubber matrix, the $d$ spacing of the silicate layers tended to remain similar to its original size. This was because the dispersion became poor at high levels of the filler loading. Some of the filler particles tended to aggregate or agglomerate, forming big structures in the rubber matrix. Thus, the possibility of rubber chains diffusing into the silicate layer spacing was significantly lowered at high filler loading. 
From the XRD analysis shown above, it emerged that the dispersion state of the filler in the clay/SR nanocomposites prepared via the melt mixing process was highly dependent on the level of the clay concentration regardless of the initial $d$ spacing of the clay's interlayers. On average, the intercalation/exfoliation morphology in the SR nanocomposites was achieved at very low loading of the clay filler, i.e. $4 \mathrm{phr}$ to $8 \mathrm{phr}$. This result contradicted the previous findings $[3,6]$. Because of the low viscosity of SR, most researchers believed that melt intercalation would occur favourably at high loading of OMMT (organoclays) [3, 6]. According to some authors, increase in viscosity at high dosage of OMMT would provide effective shearing forces within the rubber to facilitate the intercalation of the SR chains into the interlayer spacing of OMMT. However, a significant improvement in the mechanical properties of the rubber vulcanizate was not achieved because of the formation of filler agglomerates in the rubber $[3,6]$.

Dispersion state of different clays in the rubber at a constant filler loading

In this study, the dispersion of three types of clays with different initial layer spacing at a constant loading of $6 \mathrm{phr}$ in silicone rubber was investigated. Fig. 2 shows the XRD spectra of the pristine clay (Cloisite $\mathrm{Na}^{+}$), organoclays (Cloisite 30B and Cloisite 20A) and clay/SR nanocomposites filled with a fixed filler loading of $6 \mathrm{phr}$. It appeared that the 
nanocomposites containing Cloisite $\mathrm{Na}^{+}$(a-i) and Cloisite 30B (b-i) showed no peak at all on their corresponding spectra and this implied that the filler had exfoliated in the rubber matrix. In contrast, the Cloisite 20A/SR nanocomposite $(\mathrm{c}-\mathrm{i})$ had a sharp peak between $2 \theta=2.3-2.5^{\circ}$ with an inter-layer spacing $\left(\mathrm{d}_{001}\right)$ of $3.46 \mathrm{~nm}$. The result suggested that the interlayer spacing had expanded by about $0.89 \mathrm{~nm}$ from the original size and this indicated intercalation. Surprisingly, Cloisite 30B exfoliated in the rubber matrix in spite of having a smaller initial interlayer spacing compared with Cloisite 20A. Note that Cloisite 20A intercalated in the rubber matix. Therefore, it was concluded that Cloisite 20A which had a larger interlayer spacing did not necessarily exfoliate easily in the rubber matrix compared with Cloisite 30B under the same mixing condition.

More interestingly, since pure MMT $\left(\right.$ Cloisite $\mathrm{Na}^{+}$) exfoliated in the rubber matrix without any treatment or modification, this suggested that reducing the dispersive energy by organic pre-treatment had little benefit for improving the dispersion of the filler in the SR nanocomposites prepared by melt-mixing technique. This result is in agreement with Vaulot and co-workers [4] who reported that the compatibilization of clay filler and geometrical considerations were not sufficient requirements to achieve exfoliation in polydimethylsiloxane rubber. These authors proposed that a specific interaction between the 
reactive polymer end groups and the filler surface played an important role in the exfoliation of the filler and interestingly this conclusion was also supported by a calorimetric approach.

In this study, exfoliation of the filler was achieved in the Cloisite $\mathrm{Na}^{+} / \mathrm{SR}$ nanocomposite, thus the hydrophilic nature of the pure clay highlighted the role of hydroxyl groups $(\mathrm{OH})$ in the exfoliation process. It was believed that the formation of exfoliated structure in the Cloisite $\mathrm{Na}^{+} / \mathrm{SR}$ nanocomposite was attributed to interaction between the hydroxyl groups from the clay and the silicone rubber. Since, the silicone rubber used in this study contained vinyl groups, therefore in this case the contribution from the end-groups was diminished due to the lesser attraction of the apolar groups such as vinyl [4]. However, the polar hydroxyl groups $(\mathrm{OH})$ inside the clay galleries had a high tendency to interact with the siloxane segments ( $\mathrm{Si}-\mathrm{O}-\mathrm{Si}$ ) of the silicone rubber backbone to form hydrogen bonding. It was believed that such interaction might have played a key role in determining the clay dispersion in the rubber matrix. Since the hydrogen bonds between the rubber chains and clay surface were strong enough to overcome the attractive Van der Waals forces holding the clay layers together, this helped to separate the clay layers into single platelets in the rubber matrix. 
Cloisite 30B was modified with MT2EtOH that contained hydroxyl groups. It was feasible that the $\mathrm{OH}$ groups in the Cloisite $30 \mathrm{~B}$ interacted with the siloxane groups in the silicone rubber chains, leading to exfoliation. On the other hand, Cloisite 20A lacked surface active groups such as hydroxyl groups on the platelet surface and also in the organic modifier because it was modified with quaternary ammonium (2M2HT). Thus, this prevented Cloisite $20 \mathrm{~A}$ from interacting favourably with the siloxane groups in the silicone rubber chains and consequently exfoliation of the clay particles did not occur.

\section{Dispersion mechanism of the clay particles in rubber matrix}

It is tempting at this point to identify the exfoliation mechanism of the clays in the clay/SR nanocomposites. It is critical to find out how exfoliation of the clay particles in the rubber occurred and what mechanism it had. Initially, we investigated effects of the mixing condition on the clay dispersion in the rubber. The experiment was carried out at two different mixing times while other factors were kept constant. Fig. 3 compares the XRD spectra of the cured nanocomposites mixed for 3 minutes and 15 minutes, respectively. It was noticed that the dispersion of the clays in the rubber was unaffected by increasing the mixing time. The absence of any peaks on the spectra suggested that exfoliation had occurred in the Cloisite $\mathrm{Na}^{+} / \mathrm{SR}$ nanocomposite and Cloisite 30B/SR nanocomposite after 3 min mixing. 
However, a mixing time of 15 min was considered in making the rubber compounds because it was more convenient when using a small laboratory intermixer.

Curing is the final stage in the processing of rubber nanocomposites. Thus, it was of significant interest to investigate effect of high temperature cure on the dispersion of the clays in the rubber. Fig. 4 shows the XRD spectra of the Cloisite $\mathrm{Na}^{+} / \mathrm{SR}$ nanocomposite before curing (after melt mixing) and after curing at $160{ }^{\circ} \mathrm{C}$. The uncured nanocomposite exhibited a broad peak at a similar position as the pure Cloisite $\mathrm{Na}^{+}$at $2 \theta=7.23$ (Fig. 4b). This indicated that the clay had not exfoliated. However, after curing the structure of the clay changed dramatically. The peak on the XRD spectrum of the cured nanocomposite disappeared. This indicated that most of the clay particles exfoliated during the high temperature curing process. A similar feature was also seen for the Cloisite 30B/SR nanocomposite (Fig. 5). Before curing, a peak was clearly observed on the XRD spectrum (Fig. 5b) roughly where a peak appeared for the pure Cloisite 30B (Fig. 5a). However, after curing there was no peak on the XRD spectrum of the nanocomposite, which indicated high exfoliation of the clay particles in the rubber matrix (Fig. 5c).

The dispersion state of the clay in the Cloisite 20A/SR nanocomposite (Fig.6a-c) was noticeably different from that seen in the Cloisite $\mathrm{Na}^{+} / \mathrm{SR}$ and Cloisite $30 \mathrm{~B} / \mathrm{SR}$ 
nanocomposites. Before curing the rubber, the XRD peak appeared at $2 \theta=1.56^{\circ}$ (Fig.6b), which corresponded to $5.66 \mathrm{~nm} d$ spacing. However, for the original Cloisite 20A clay the major peak appeared at $2 \theta=3.42^{\circ}$ (Fig. 6a) which corresponded to $2.57 \mathrm{~nm} d$ spacing. The large difference between the $d$ spacing of the clay particles, i.e. $3.09 \mathrm{~nm}$, before curing suggested that the rubber chains had intercalated into the clay gallery under the shear forces present during mixing. However after curing the rubber, the XRD peak appeared at $2 \theta=$ $2.55^{\circ}$ which corresponded to $3.46 \mathrm{~nm} d$ spacing (Fig. 6c), which was lower than the $d$ spacing measured for the uncured rubber at $5.66 \mathrm{~nm}$ (Fig. 6b). Clearly, there was a reduction of 2.2 $\mathrm{nm}$ in $d$ spacing which indicated that the rubber chains were pulled out of the interlayer spacing during the curing process. However, in spite of this reduction, there was intercalation of the clay particles by the rubber chains in the Cloisite 20A/SR nanocomposites.

The clay dispersion in the rubber before and after curing was also investigated by optical microscopy (Figs. 7a \& 7b). The dispersed Cloisite $\mathrm{Na}^{+}$particles in the uncured compound can clearly be observed as black dots in the micrograph (Fig. 7a). However, after curing there were little black dots in the micrograph and this implied that most of the clay particles had dispersed and exfoliated in the rubber matrix. This observation was in line with 
the results shown in Figs. 4(a-c), which also showed exfoliation of the clay particles to have taken place during the curing process.

These findings were also supported by differential scanning calorimetry (DSC) data as shown in Fig. 8. As can be seen, the exothermic peaks for both the pure rubber and CloisiteNa ${ }^{+} / \mathrm{SR}$ anocomposite appeared at about $155^{\circ} \mathrm{C}$, which was above the decomposition temperature of dicumyl peroxide (DCP). Thus, this indicated that the heat released was generated from the curing reaction. Moreover, the heat or energy involved in such a reaction could be determined by integrating the area of the calorimetric peak. In this case, when the two exothermic peaks were compared, it was found that the heat of reactions $\Delta \mathrm{H}_{2}$ of the nanocomposite was $26 \%\left(\left(\Delta \mathrm{H}_{2}=44.1 \mathrm{~J} / \mathrm{g}-\Delta \mathrm{H}_{1}=34.9 \mathrm{~J} / \mathrm{g}\right) \times 100\right)$ higher than that of the unfilled rubber. This trend showed that more heat was released from the nanocomposite due to the energy involved in the exfoliation of the clay particles in the rubber.

Hence, when the results from the XRD analysis, optical microscopy and DSC were considered, it was concluded that the exfoliation of the clays could not be reasonably described using the layer-by-layer mechanism as proposed for most rubber nanocomposites [12]. It may therefore be assumed that the exfoliation of the clays occurred by a number of mechanisms. It seemed that to some extent, the exfoliation mechanism in melt-intercalation 
depended on the thermodynamic free energy provided that the interaction between the rubber chains and clay platelet was favourable. This approach had been explained in depth by Vaia and Ginannelis based on the free energy profiles [21].

Cure characteristics of the clay/SR nanocomposites

Table 3 summarizes the cure characteristics of the clay/SR nanocomposites. Effect of the clay type and clay loading on the scorch time, $\mathrm{t}_{\mathrm{S} 2}$, optimum cure time, $\mathrm{t}_{95}$, the maximum and minimum torques $\left(\mathrm{M}_{\mathrm{H}}\right.$ and $\mathrm{M}_{\mathrm{L}}$, respectively), and $\Delta$ torque $\left(\Delta\right.$ torque $\left.=\mathrm{M}_{\mathrm{H}}-\mathrm{M}_{\mathrm{L}}\right)$ was investigated. For the Cloisite 30B/SR and Cloisite 20A/SR nanocomposites, the scorch and optimum cure times changed noticeably in comparison with the pure SR. For example, for the Cloisite 30B/SR nanocomposite, the scorch time decreased by approximately $21 \%$ at $12 \mathrm{phr}$ filler loading. Similarly, for the Cloisite 20A/SR nanocomposite, there was a reduction of $18 \%$ in the scorch time at the same filler laoding.

On the other hand, the optimum cure time increased gradually as the filler loading was raised. For instance, the largest increase was recorded for the Cloisite 20A/SR nanocomposite with $12 \mathrm{phr}$ filler. These changes were attributed to the ability of the peroxide radicals to react with the functional groups of the organic surfactants in the Cloisite $30 \mathrm{~B}$ and Cloisite 20A organoclays that consequently affected the vulcanisation times. A similar 
observation was also reported regarding the effect of organic modified clays on the vulcanization process of clay/SR nanocomposites but with a different curing system. Voulomenou and Tarantili [1] claimed that there was a possible interaction between the curing agent and the organic moiety on the organoclay surface instead of a interaction between the curing agent and the rubber chains, which resulted in an increase in the vulcanisation time. However, this phenomenon was not seen when untreated clay (Cloisite $\mathrm{Na}^{+}$) was used in the rubber.

The minimum torque $\left(\mathrm{M}_{\mathrm{L}}\right)$, maximum torque $\left(\mathrm{M}_{\mathrm{H}}\right)$ and $\Delta$ torque of the nanocomposites and pure SR were also compared. In all cases, inclusion of the fillers in the rubber increased the $\mathrm{M}_{\mathrm{L}}$, which related to improved viscosity. Note that both the maximum torque $\left(\mathrm{M}_{\mathrm{H}}\right)$ and $\Delta$ torque are indication of crosslink density changes in the rubber. The incorporation of Cloisite $\mathrm{Na}^{+}$into the rubber increased the $\mathrm{M}_{\mathrm{H}}$ and $\Delta$ torque by about $13 \%$ and $12 \%$, respectively when the filler loading reached $12 \mathrm{phr}$. The increase of $\mathrm{M}_{\mathrm{H}}$ and $\Delta$ torque with the clay loading suggested that the pristine MMT increased the crosslink density of the rubber and consequently raised the stiffness and modulus of the nanocomposite.

However, the inclusion of Cloisite 30B and Cloisite 20A had an adverse effect on the $\mathrm{M}_{\mathrm{H}}$ and $\Delta$ torque of the rubber. It can be seen that both $\mathrm{M}_{\mathrm{H}}$ and $\Delta$ torque values of these 
nanocomposites steadily declined as a function of the filler loading. As mentioned earlier, there is a possibility that the reactive functional groups in the organoclays interfered with the curing process by reacting with the free radicals of peroxide. As a result, there was less peroxide left to react with the rubber chains to form crosslinks and this reduced the extent of the cure in the rubber. Similar results with regard to the effect of unmodified clay (MT) and organically modified clay (OMMT) fillers on the curing properties of a silicone rubber were reported by Kaneko and Yoshida [3]. They proposed that the increase of crosslink density in PDMS/MT was attributed to a nucleation reaction between Si-OH groups on the MT clay and the Si atoms of the silicone rubber chains. They concluded that the silanol-terminated PDMS fragments and the silicone rubber chain scission were formed from this reaction. The chain fragments were then interacted with other hydroxyl groups from other silicone chains or even with the hydroxyls on the MT clay surface and finally this resulted in an increase in the crosslink density of the rubber.

Mechanical properties of the clay/SR nanocomposites as a function of the clay loading

The Young's modulus, tensile strength, hardness, elongation at break and store energy density at break of the pure SR and clay/SR nanocomposites are presented as a function of the loading of the fillers in Figs. 9(a-e). As expected, the pure SR possessed very poor 
mechanical properties and this was attributed to the structure of the rubber, which could not readily strain crystallise on stretching. However, the mechanical properties of the rubber improved significantly when the fillers were added. The Young's modulus and tensile strength of the Cloisite $\mathrm{Na}^{+} / \mathrm{SR}$ nanocomposite were higher than those of the Cloisite $30 \mathrm{~B} / \mathrm{SR}$ and Cloisite 20A/SR nanocomposites with increasing the filler loading. For instance, the addition of up to $12 \mathrm{phr}$ Cloisite $\mathrm{Na}^{+}$improved the Young's modulus to $0.45 \mathrm{MPa}$ from 0.28 MPa (pure SR) which was an improvement of about $60 \%$ (Fig 9a). Similarly, the tensile strength of the rubber increased by more than $100 \%$ when the loading of Cloisite $\mathrm{Na}^{+}$reached $12 \mathrm{phr}$ (Fig. 9b). This was a major improvement in these properties.

The enhancement of the Young's modulus and tensile strength was due to the presence of the exfoliated clays in the rubber matrix. As shown by the XRD spectra, Cloisite $\mathrm{Na}^{+}$had a high tendency to produce a mixture of exfoliated and partially exfoliated microstructures as compared with the other fillers. In the exfoliated state, majority of the clay particles were single platelets (average platelet thickness $\sim 0.94 \mathrm{~nm}$ and average platelet length $\sim 91 \mathrm{~nm}$ ) [14]. When the high aspect ratio of the exfoliated platelet is considered, a significant effect in the load transfer from rubber matrix to a single clay platelet could be envisaged, which explained the increases observed in the elastic modulus of the nanocomposites. In addition, 
the strong interfacial interaction between Cloisite $\mathrm{Na}^{+}$and rubber was vastly beneficial to the reinforcement effect. According to Schmidt and Giannelis [22], the interfacial strength in clay/SR nanocomposite was derived from the silanol and siloxane interactions with few hydroxyl groups $(\mathrm{OH})$ that were present at the edges of the natural montmorillonite platelets and siloxane bonds in the PDMS chains. This conclusion was also supported by the sum of the equilibrium solvent uptake and mechanical properties measured.

It was interesting to note that the exfoliated Cloisite 30B/SR nanocomposites did not possess particularly high Young's modulus and tensile strength even though an excellent filler dispersion was seen in the rubber. This was because most of the Cloisite $30 \mathrm{~B} / \mathrm{SR}$ nanocomposites possessed low crosslink density due to interference by the organic surfactant, hence the poor mechanical properties of the nanocomposites. Moreover, only a modest improvement in the mechanical properties was observed in the Cloisite 20A nanocomposites as the loading of the filler was increased. As mentioned earlier, most of the Cloisite 20A had a tendency to form intercalated structures in the rubber matrix. In an intercalated structure, the effect of load transfer from the matrix to the platelets was less efficient than in the exfoliated one. This was because the load from the matrix was transferred through the stacking platelets thus reducing the load transfer capability from the matrix to the particles. In 
addition, the low reinforcing ability of the intercalated Cloisite $20 \mathrm{~A}$ was due to the lower surface area of the stacked clay platelets. As a result, the filler-matrix stress transfer was diminished by reducing the effective surface area [23]. Therefore, this explained why the intercalated nanocomposites exhibited inferior Young's modulus and tensile strength to the exfoliated ones.

As shown in Fig. 9c, the increase in hardness was consistent with increases in the Young's modulus of the nanocomposites. A significant improvement in the hardness from 18 Shore A (pure SR) to 22 Shore A was measured for the Cloisite $\mathrm{Na}^{+} / \mathrm{SR}$ nanocomposite as a function of the clay loading. In contrast, the hardness of the Cloisite 30B/SR and Cloisite 20A/SR nanocomposites did not improve any more above the 4 phr loading of the fillers and remained essentially unchanged with further increases in the loading of the fillers. However, the inclusion of these fillers did improve the hardness when the results were compared with that of the pure SR which was 18 Shore A. Since hardness is influenced also by crosslink density, the lower hardness of these two nanocomposites was attributed to a lower crosslink density as indicated by the $\Delta$ torque values in Table 3 .

Furthermore, the elongation at break of the nanocomposites improved significantly with the addition and progressive increases in the loading of the clays, irrespective of the type 
of the clay used as seen in Fig. 9d. There was a large improvement in the elongation at break of the Cloisite 20A/SR nanocomposite particularly at high filler loadings. For example, the elongation at break improved by $64 \%$ when $8 \mathrm{phr}$ of the filler was incorporated into the rubber. Notably, there was no further improvement in this property when the loading of the filler reached $12 \mathrm{phr}$. The Cloisite 30B/SR and Cloisite $\mathrm{Na}^{+} / \mathrm{SR}$ nanocomposites exhibited a similar trend but the values were lower for the latter. These results indicated that the elongation at break was influenced to a great extent by the dispersion of the clays in the rubber matrix. On this basis, intercalated Cloisite 20A improved the elasticity of the elastomeric matrix more significantly than the exfoliated Cloisite $30 \mathrm{~B}$ and Cloisite $\mathrm{Na}^{+}$did. However, the crosslink density had even a bigger influence on the rubber properties. For example, the inferior elongation at break of the Cloisite $\mathrm{Na}^{+} / \mathrm{SR}$ nanocomposite was due to higher stiffness even though the dispersion of the filler in the rubber was similar to that of Cloisite 30B. Therefore, it was concluded that the elongation at break was dependent on the state of dispersion of the clays as well as the crosslink density of the rubber.

Stored energy density at break is a measure of the energy stored per unit volume in the rubber before the sample finally breaks. It is important to measure this property because it indicates the resistance of the rubber to crack initiation and growth. As mentioned earlier, in 
this experiment, the stored energy density at break was calculated from the area under the stress-strain curve using the trapezium rule. Fig. 9e shows results for the pure SR and clay/SR nanocomposites as a function of the clay content. As can be seen, the addition of the fillers improved the stored energy density at break of the rubber substantially. But this property marginally improved for the Cloisite 20A/SR and Cloisite 30B/SR nancomposites when the loading of the fillers was increased from 4 to $6 \mathrm{phr}$ in the rubbers. The stored energy density at break continued increasing in the following order, Cloisite20A/SR nanocomposite > Cloisite30B/SR nanocomposite $>$ CloisiteNa ${ }^{+} / \mathrm{SR}$ nanocomposite as the loading of the fillers was raised further from 8 to $10 \mathrm{phr}$. Interestingly, there was no additional improvement in the stored energy density at break of the Cloisite 20A/SR nancomposite when the loading of the filler was increased to $12 \mathrm{phr}$.

Hysteresis in the pure SR and clay/SR nanocomposites

When rubber is deformed, it stores energy but because it is a visco-elastic material, some of the energy is dissipated as heat in the rubber and this is termed hysteresis. Hysteresis is measured from the area under a stress versus strain graph which is produced in a single stress-strain cycle. In order to measure hysteresis in the rubbers, standard dumbbell test 
pieces were cycled repeatedly up to 10 cycles at different strain amplitudes, reaching $400 \%$ to generate stress-strain traces. The rubbers used were unfilled and contained $6 \mathrm{phr}$ of the fillers.

Fig. 10 shows typical stress-strain curves for the unfilled rubber after the $1^{\text {st }}$ cycle at different strain amplitudes and the hysteresis loops from which the energy loss in the rubber was calculated. As can be seen in Fig. 10, the hysteresis loop enlarged as the level of the applied strain amplitude on the rubber was raised. This indicated that the energy dissipated in the rubber was depended on the level of the applied strain amplitude. For the rubbers tested, at a given strain amplitude the energy loss after the $1^{\text {st }}$ cycle was significantly larger in magnitude than that in the $10^{\text {th }}$ cycle (Table 4 ). For example, for the pure SR the energy loss dropped by approximately $59 \%$ at $400 \%$ strain amplitude. A similar trend was also observed for the clay/SR nanocomposites irrespective of the clay types. For instance, the energy loss in the Cloisite 20A/SR nanocomposite decreased by up to $67 \%$ after $10^{\text {th }}$ cycle at $400 \%$ strain amplitude.

Generally, fillers cause energy dissipation or hysteresis in rubber. Clearly in this case, the inclusion of the clays induced more energy dissipation when compared with the pure SR. However, the Cloisite 30B/SR and Cloisite $\mathrm{Na}^{+} / \mathrm{SR}$ nanocomposites displayed lower energy loss when compared with the intercalated Cloisite 20A/SR nanocomposite as shown in Table 
4. For example, in the $1^{\text {st }}$ cycle at $400 \%$ strain amplitude, the intercalated Cloisite $20 \mathrm{~A} / \mathrm{SR}$ nanocomposite had a energy loss of about $174 \mathrm{~mJ} / \mathrm{m}^{3}$ whereas the exfoliated Cloisite $\mathrm{Na}^{+} / \mathrm{SR}$ and Cloisite 30B/SR nancomposites had energy losses at 139 and $161 \mathrm{~mJ} / \mathrm{m}^{3}$, respectively. There are two possible mechanisms to explain this phenomenon. In a nanocomposite, the energy loss is caused by internal friction between macromolecular chains and the friction between rubber chains and layered clay. For an exfoliated nancomposite, high surface area of a single clay platelet generates stronger interaction with the rubber chains. This contributes to less frictional movement between the two during the deformation process. As a result, only a small energy is dissipated as heat in the exfoliated nanocomposite. However, in an intercalated morphology there is much less interaction between the rubber chains and the clay platelets and therefore the rubber chains are free to move when deformation is applied. This free movement will generate more frictional heating or hysteresis in the rubber.

From the results, it can be seen that hysteresis in the nanocomposites depended strongly on the state and dispersion of the clay fillers in the rubber. The nanocomposites containing exfoliated clays exhibited low hysteresis compared with the one containing intercalated clays (Table 4). This finding is in line with the previous works reported for polyurethane $(\mathrm{PU}) /$ clay nanocomposite $[24,25]$. The authors proposed that the energy 
dissipation in the PU/clay nanocomposite was determined by the viscoelastic nature of the pure PU chains and also the orientation of the silicate layer platelets [24, 25]. Notably, a similar trend was also seen in some PDMS rubbers filled with precipitated silica which showed that a strong interaction between the filler particles and rubber chains contributed to low hysteresis as shown in the dynamic properties [26].

\section{CONCLUSION}

Based on the XRD analysis, it was shown that the dispersion state of the clays in the clay/SR nanocomposites prepared via melt-mixing process was dependent on the level of the clay concentration. Formation of highly exfoliated and intercalated nanocomposites was achieved at low filler loading, i.e. $<8 \mathrm{phr}$, and above this level partially exfoliated structures were formed. Moreover, it was evident that the formation of exfoliated structure in the clay/SR nanocomposites was a spontaneous process that happened during the vulcanisation stage.

In addition, the increase in the Young's modulus, tensile strength and hardness was mainly due to the presence of exfoliated particles in the rubber matrix and formation of crosslinks which also played an important role in determining the overall performance of the rubber vulcanizates. Thus, the findings suggest that a balance between dispersion of the clay 
particles and crosslink density is essential to achieve good reinforcement in clay/SR nanocomposites. Finally, it may be concluded that the findings from this study could help to advance our understanding of the way clays reinforce the processing and mechanical properties of silicone rubber and assist future work on this fascinating subject.

\section{REFERENCES}

1. A. Voulomenou, P.A. Tarantili, J. Appl. Polym. Sci., 118, 2521 (2010).

2. S. D. Burnside and E. P. Giannelis, J. Polym. Sci. Part B: Polym. Phys., 38, 1595 (2000).

3. M. L. Q. A Kaneko and I. V. P Yoshida, J. Appl. Polym. Sci., 108, 2587 (2008).

4. C. Vaulot, P. Ziegler and B. Haidar, Polymer, 52, 700 (2011).

5. M. L. Q. A. Kaneko, R. B. Romero, M.C. Gonçalves and I. V. P. Yoshida, Eur. Polym. J., 46, 881 (2010).

6. C. Jia, L. Q. Zhang, H. Zhang and Y. L. Lu, Poly. Comp., 32, 1245 (2011).

7. D. Schmidt, F. Clement and E. P. Giannelis, Adv. Funct. Mater., 16, 417 (2006).

8. J. Wang, Y. Chen and Q. Jin, Macromol. Chem. Phys., 206, 2512 (2005).

9. J. Shah, Q. Yuan and R.D.K. Misra, Mat. Sci. Eng. A., 523, 199 (2009).

10. T.P. Chua, M. Mariatti, A. Azizan and A.A. Rashid, Compos. Sci. Techol., 70, 671 
(2010).

11. R. Verdejo, C. Saiz-Arroyo, J., Carretero-Gonzalez, F. Barroso-Bujans, M. A.

Rodriguez- Pereza and M. A. Lopez-Manchado, Eur. Polym. J., 44, 2790 (2008).

12. R. Sengupta, S. Chakraborty, S. Bandyopadhyay, S. Dasgupta, R. Mukhopadhyay, K.

Auddy and A.S. Deuri, Polym. Eng. Sci., 47, 1956 (2007).

13. R. Stephen and S. Thomas, Rubber nanocomposites: preparation, properties and applications, Chapter 1, John Wiley \& Sons, Inc. New Jersey (2010).

14. D. R Paul and L. M. Robeson, Polymer, 49, 3187 (2008).

15. J. P. Lewicki, J. J. Liggat and M. Patel. Polym. Degrad. Stabil., 94, 1548 (2009).

16. C. Labruyère, G. Gorrasi, F. Monteverde, M. Alexandre and Ph. Dubois, Polymer, 50, 3626 (2009).

17. S. Horsch, G. Serhatkulu, E. Gulari and R. M. Kannan, Polymer, 47, 7485 (2006).

18. M. W. Simon, K. T. Stafford and Duan Li Ou, J. Inorg. Organomet. Polym., 18, $364(2008)$.

19. N. Roy and A. K. Bhowmick. Polymer, 51, 5172 (2010).

20. S. Pavlidoua and C. D. Papaspyride, Prog. Polym. Sci., 33, 1119 (2008).

21. R. A. Vaia and E.P. Giannelis, Macromolecules, 30, 7990 (1997). 
22. D. Schmidt and E.P. Giannelis, Chem. Mater., 22, 167 (2010).

23. V. Molajavadi and H. Garmabi, e-Polymers, 20, 1 (2011).

24. J. Jin, M. Song, K.J. Yao and L. Chen, J. Appl. Polym. Sci., 99, 3677 (2006).

25. M. Song and H. Xia, Polym. Int., 55, 229 (2006).

26. S. E. Shim and A.I. Isayev, Rheol. Acta, 43, 127 (2003). 
TABLE 1. Formulations of Clay/SR nanocomposites. phr (part per hundred rubber by weight)

\begin{tabular}{cccc}
\cline { 2 - 4 } Formulation & $1^{\text {st }}$ series & $2^{\text {nd }}$ series & $3^{\text {rd }}$ \\
\hline Silicone rubber (SR) & 100 & 100 & 100 \\
Peroxide & 0.3 & 0.3 & 0.3 \\
Cloisite $\mathrm{Na}^{\mathbf{T}}$ & $4,6,8,10,12$ & 0 & 0 \\
Cloisite 30B & 0 & $4,6,8,10,12$ & 0 \\
Cloisite 20A & 0 & 0 & $4,6,8,10$ \\
& & & 12 \\
\hline
\end{tabular}


TABLE 2. XRD

of Cloisite 20A and Cloisite 20A/SR data nanocomposites.

\begin{tabular}{llcc}
\hline Samples & $2 \theta$ & $\mathrm{d}(\mathrm{nm})$ & $\Delta \mathrm{d}(\mathrm{nm})$ \\
\hline Cloisite 20A & 3.428 & 2.57 & - \\
Cloisite 20A/SR - 4phr & 2.55 & 3.46 & 0.89 \\
Cloisite 20A/SR - 6phr & 2.55 & 3.46 & 0.89 \\
Cloisite 20A/SR - 8 phr & 2.82 & 3.13 & 0.56 \\
Cloisite 20A/SR - 10 phr & 2.95 & 2.99 & 0.42 \\
Cloisite 20A/SR - 12 phr & 3.00 & 2.94 & 0.37 \\
\hline
\end{tabular}


TABLE 3. Cure characteristics of pure SR and Clay/SR nanocomposites.

Cure characteristics@160 $\mathrm{C}$

\begin{tabular}{|c|c|c|c|c|c|}
\hline Samples & $\begin{array}{c}\text { Cure } \\
\text { time } \\
\mathrm{T}_{95} \\
\text { (min) }\end{array}$ & $\begin{array}{c}\text { Scorch } \\
\text { time } \\
\mathrm{T}_{\mathrm{S} 2} \\
(\mathrm{~min})\end{array}$ & $\begin{array}{l}\text { Max } \\
\text { torque } \\
(\mathrm{dNm})\end{array}$ & $\begin{array}{l}\text { Min } \\
\text { torque } \\
(\mathrm{dNm})\end{array}$ & $\begin{array}{l}\text { Delta } \\
\text { torque } \\
(\mathrm{dNm})\end{array}$ \\
\hline Pure SR & 7.24 & 3.13 & 23.19 & 1.90 & 21.29 \\
\hline Cloisite $\mathrm{Na}^{\mathrm{p}} / \mathrm{SR}-4 \mathrm{phr}$ & 7.49 & 3.28 & 24.81 & 2.00 & 22.81 \\
\hline Cloisite $\mathrm{Na}^{\mathrm{p}} / \mathrm{SR}-6 \mathrm{phr}$ & 7.23 & 3.32 & 25.42 & 2.02 & 23.40 \\
\hline Cloisite $\mathrm{Na}^{\mathrm{p}} / \mathrm{SR}-8 \mathrm{phr}$ & 6.54 & 3.25 & 25.77 & 2.25 & 23.52 \\
\hline Cloisite $\mathrm{Na}^{\mathrm{p}} / \mathrm{SR}-10 \mathrm{phr}$ & 7.33 & 3.14 & 26.42 & 2.36 & 24.06 \\
\hline Cloisite $\mathrm{Na}^{\mathrm{p}} / \mathrm{SR}-12 \mathrm{phr}$ & 8.30 & 3.24 & 26.08 & 2.29 & 23.79 \\
\hline Cloisite 30B/SR - 4 phr & 12.03 & 3.04 & 23.41 & 1.98 & 21.43 \\
\hline Cloisite 30B/SR - 6 phr & 10.14 & 2.57 & 22.52 & 1.91 & 20.61 \\
\hline Cloisite 30B/SR - 8 phr & 10.29 & 2.41 & 21.83 & 2.40 & 19.43 \\
\hline Cloisite 30B/SR - $10 \mathrm{phr}$ & 10.54 & 2.48 & 21.76 & 2.41 & 19.35 \\
\hline Cloisite 30B/SR - $12 \mathrm{phr}$ & 12.06 & 2.48 & 20.64 & 2.21 & 18.43 \\
\hline Cloisite 20A/SR - 4 phr & 7.51 & 2.59 & 22.18 & 1.89 & 20.29 \\
\hline Cloisite 20A/SR - $6 \mathrm{phr}$ & 9.28 & 2.58 & 21.16 & 1.94 & 19.22 \\
\hline Cloisite 20A/SR - $8 \mathrm{phr}$ & 10.49 & 2.60 & 19.81 & 2.70 & 17.11 \\
\hline Cloisite 20A/SR - $10 \mathrm{phr}$ & 10.21 & 2.53 & 20.51 & 2.41 & 18.10 \\
\hline Cloisite 20A/SR - $12 \mathrm{phr}$ & 12.27 & 2.54 & 19.21 & 2.48 & 16.73 \\
\hline
\end{tabular}


TABLE 4. Hysteresis or energy losses in pure SR and Clay/SR nanocomposites.

\begin{tabular}{|c|c|c|c|c|c|c|c|c|}
\hline \multirow[b]{2}{*}{ Strain amplitude } & \multirow[b]{2}{*}{$1^{\text {st }}$ cycle } & \multirow[b]{2}{*}{$10^{\text {th }}$} & \multicolumn{4}{|c|}{ Dissipated energy, $\Delta \mathrm{E}\left(\mathrm{mJ} / \mathrm{m}^{3}\right)$} & \multirow[b]{2}{*}{$1^{\text {st }}$ cycle } & \multirow[b]{2}{*}{$10^{\text {th }}$} \\
\hline & & & $1^{\text {st }}$ cycle & $10^{\text {th }}$ & $1^{\text {st }}$ cycle & $10^{\text {th }}$ & & \\
\hline $\begin{array}{l}100 \\
200\end{array}$ & $\begin{array}{c}7 \\
28\end{array}$ & $\begin{array}{r}3 \\
12\end{array}$ & $\begin{array}{c}7 \\
36\end{array}$ & $\begin{array}{r}3 \\
12\end{array}$ & $\begin{array}{l}10 \\
44\end{array}$ & $\begin{array}{r}3 \\
16\end{array}$ & $\begin{array}{l}12 \\
48\end{array}$ & $\begin{array}{r}8 \\
17\end{array}$ \\
\hline 400 & 97 & 39 & 139 & 49 & 161 & 55 & 174 & 57 \\
\hline
\end{tabular}






(a)

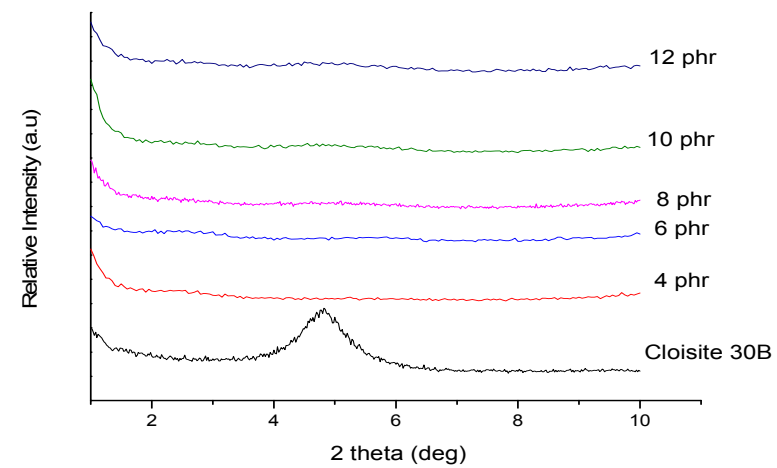

(b)

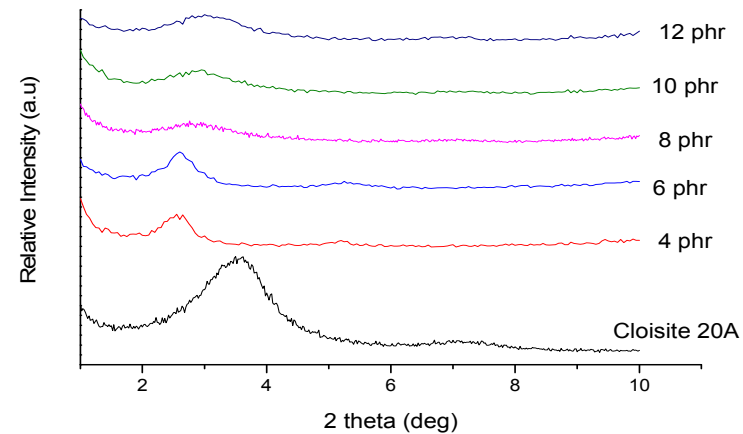

(c)

FIG. 1: XRD spectra for (a) Cloisite $\mathrm{Na}^{+} / \mathrm{SR}$ nanocomposites, (b) Cloisite 30B/SR nanocomposites, (c) Cloisite 20A/SR nanocomposites with different filler loadings. 




FIG. 2: XRD spectra of (a) Cloisite $\mathrm{Na}^{+}$, a(i) Cloisite $\mathrm{Na}^{+} / \mathrm{SR}$ nanocomposites (6 phr), (b) Cloisite 30B, b(i) Cloisite 30B/SR nanocomposites (6 phr) and (c) Cloisite 20A, c(i) Cloisite 20A/SR nanocomposites (6 phr). 


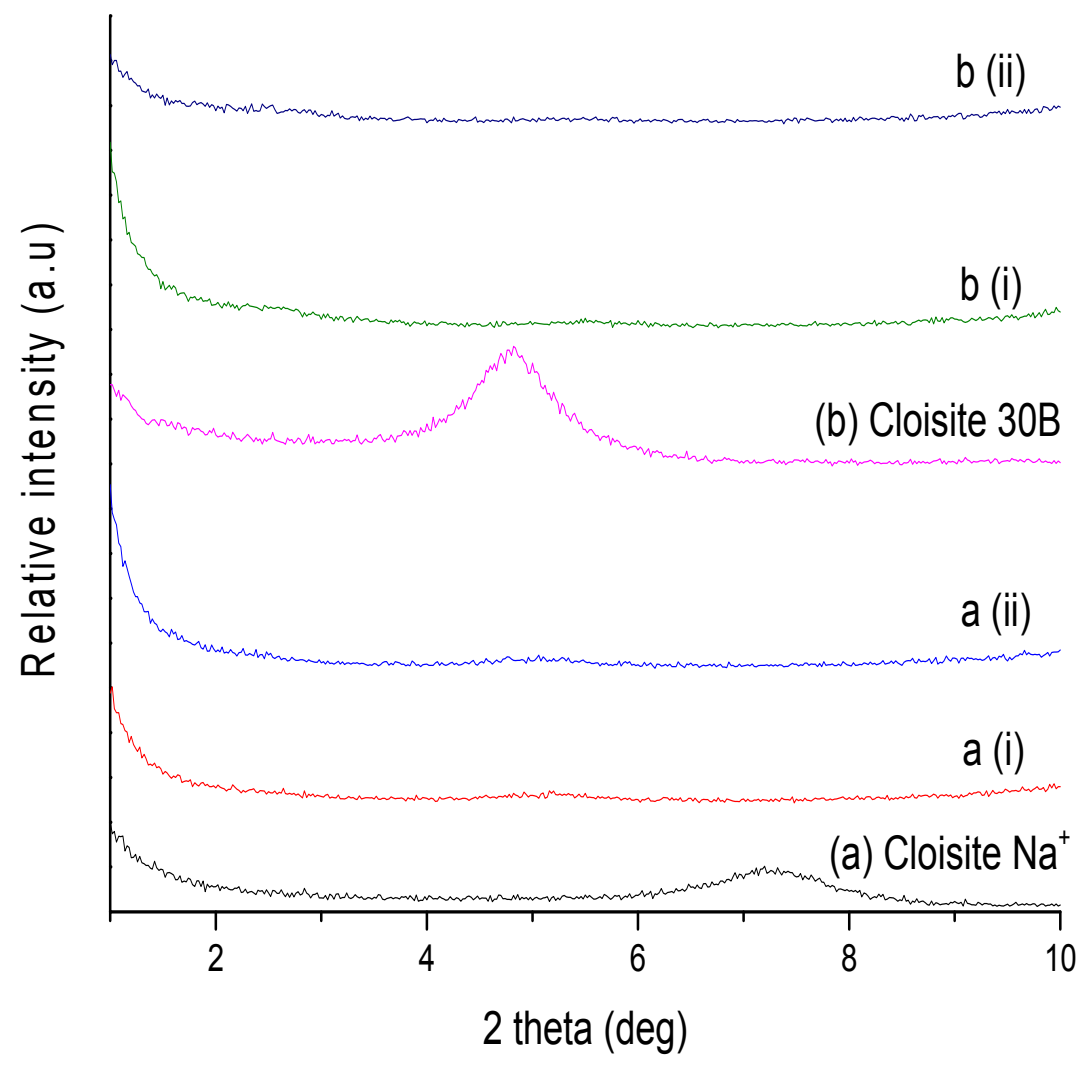

FIG. 3 : XRD spectra of (a) Cloisite $\mathrm{Na}^{+}$, a(i) Cloisite $\mathrm{Na}^{+} / \mathrm{SR}$ nanocomposite after 15 min mixing time, a(ii) Cloisite $\mathrm{Na}^{+} / \mathrm{SR}$ nanocomposite after 3 min mixing time and (b) Cloisite 30B, b(i) Cloisite 30B/SR nanocomposite after 15 min mixing time, b (ii) SR/Cloisite $30 \mathrm{~B}$ after 3 min mixing time. 


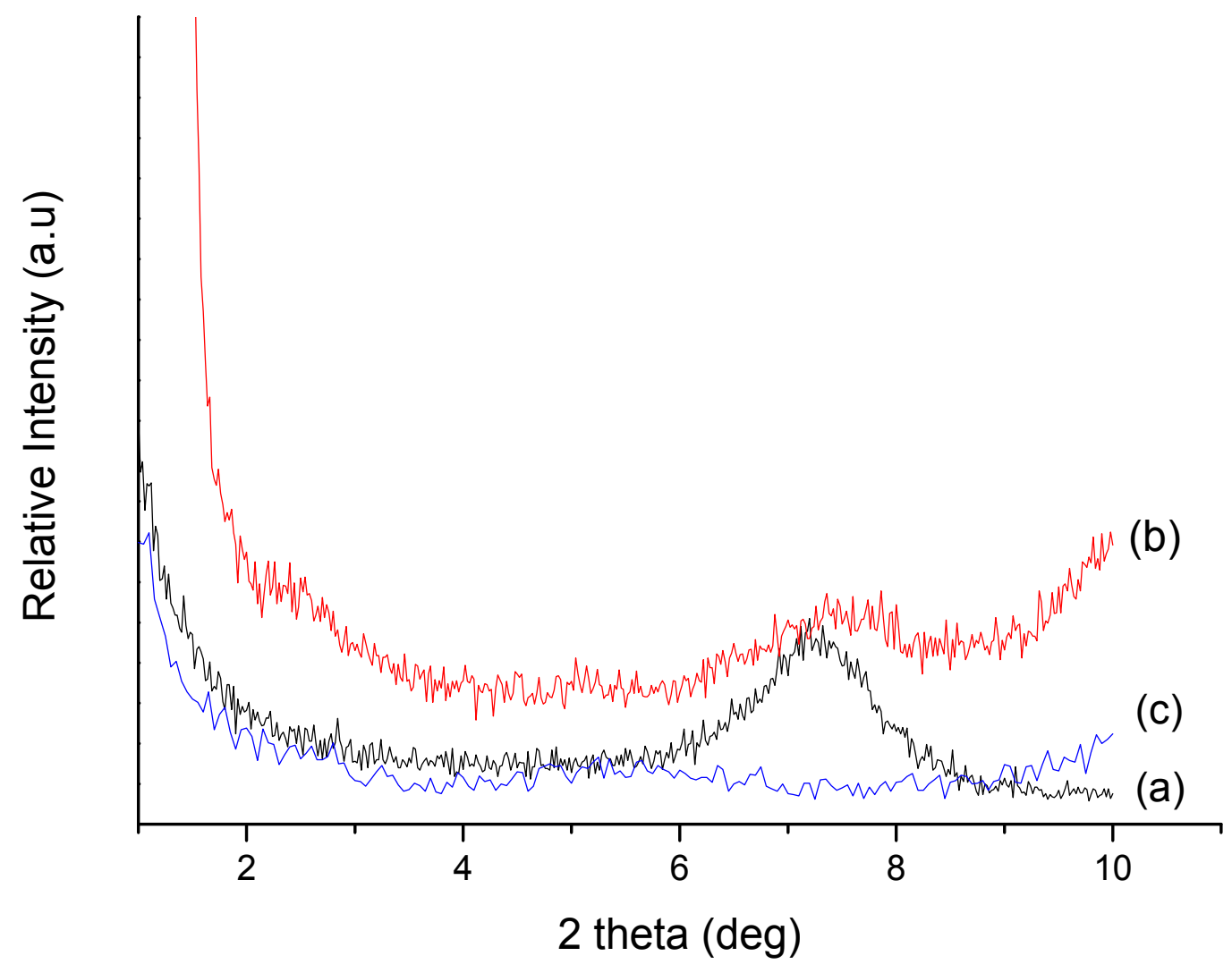

FIG. 4: XRD spectra of (a) Cloisite $\mathrm{Na}^{+}$, (b) uncured Cloisite $\mathrm{Na}^{+} / \mathrm{SR}$ nanocomposite, and (c) cured Cloisite $\mathrm{Na}^{+} / \mathrm{SR}$ nanocomposite. 


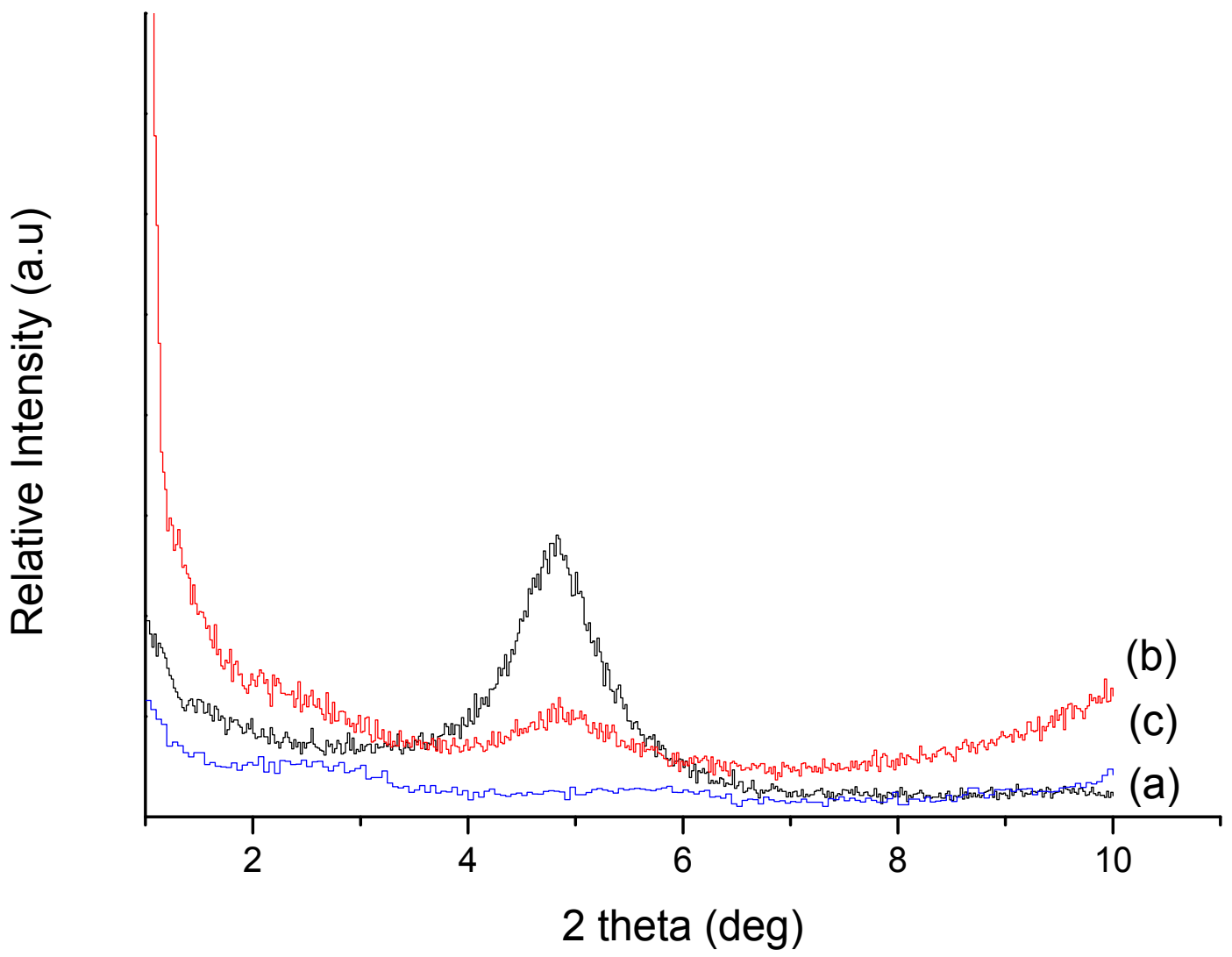

FIG. 5: XRD spectra of (a) Cloisite 30B, (b) uncured Cloisite 30B/SR nanocomposite, and (c) cured Cloisite 30B/SR nanocomposite. 


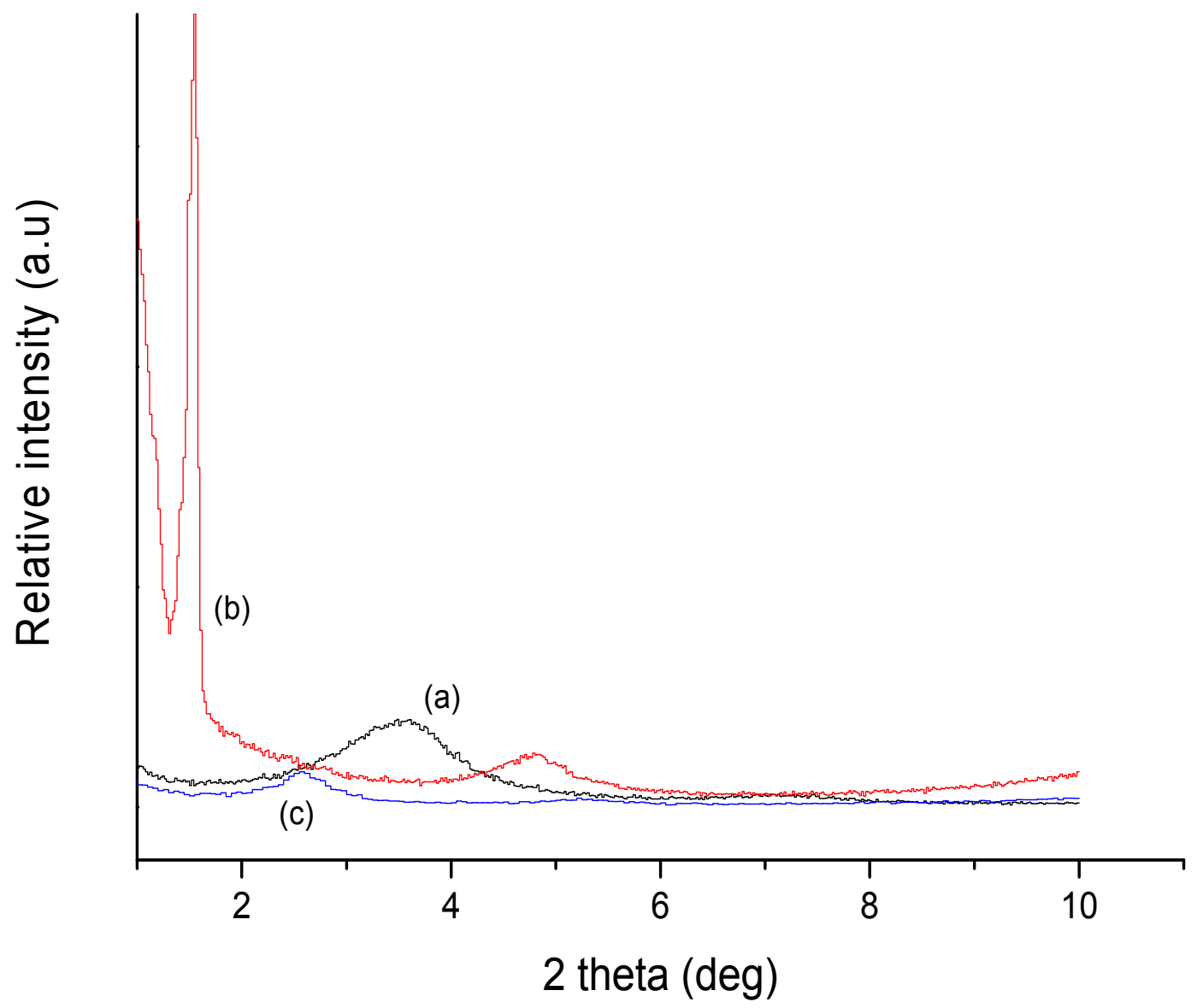

FIG. 6: XRD spectra of (a) Cloisite 20A, (b) uncured Cloisite 20A/SR nanocomposite, and (c) cured Cloisite 20A/SR nanocomposite. 

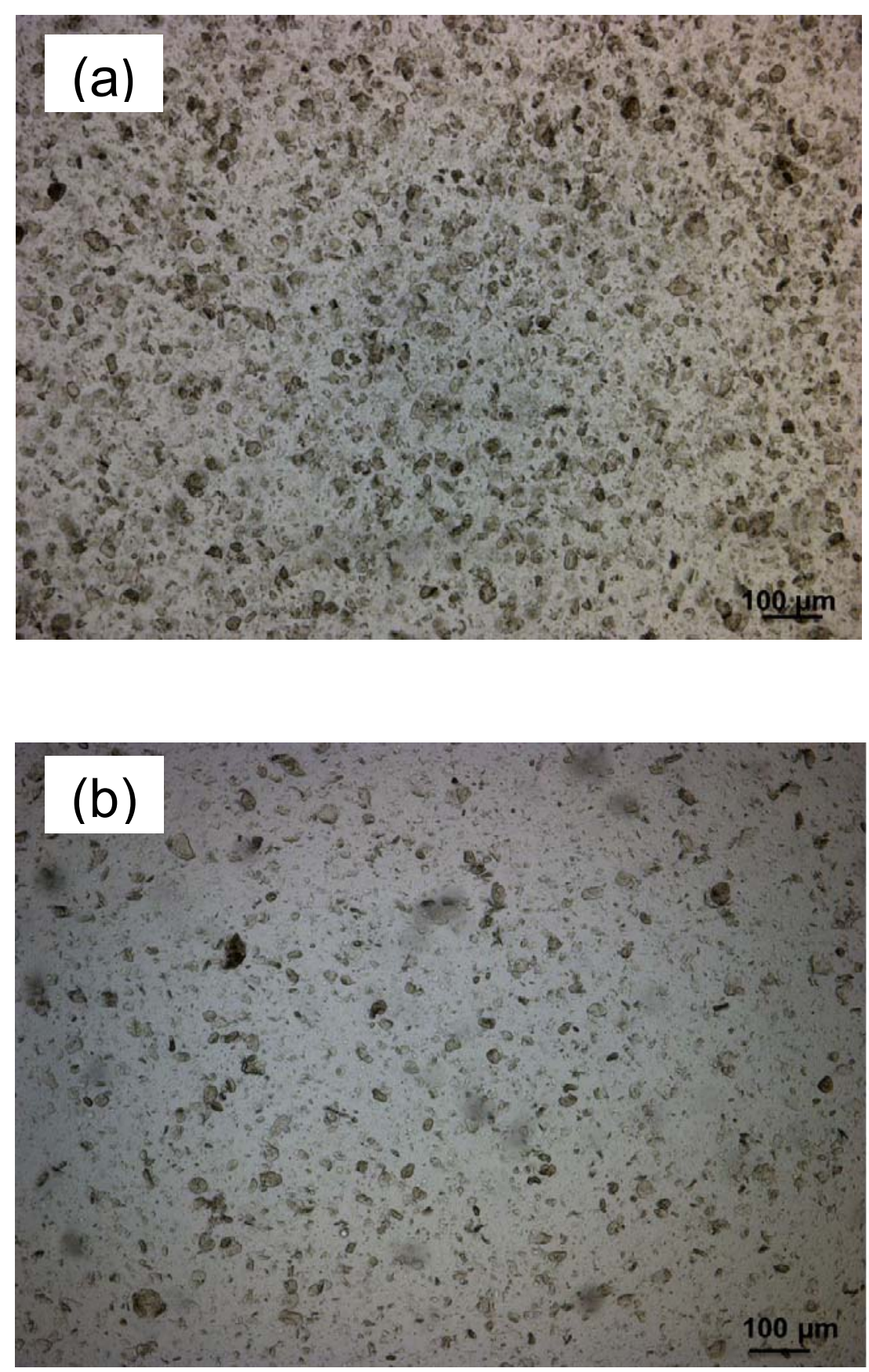

FIG.7: Optical microscopy images of (a) uncured Cloisite $\mathrm{Na}^{+} / \mathrm{SR}$ nanocomposite, (b) cured Cloisite $\mathrm{Na}^{+} / \mathrm{SR}$ nanocomposite. 


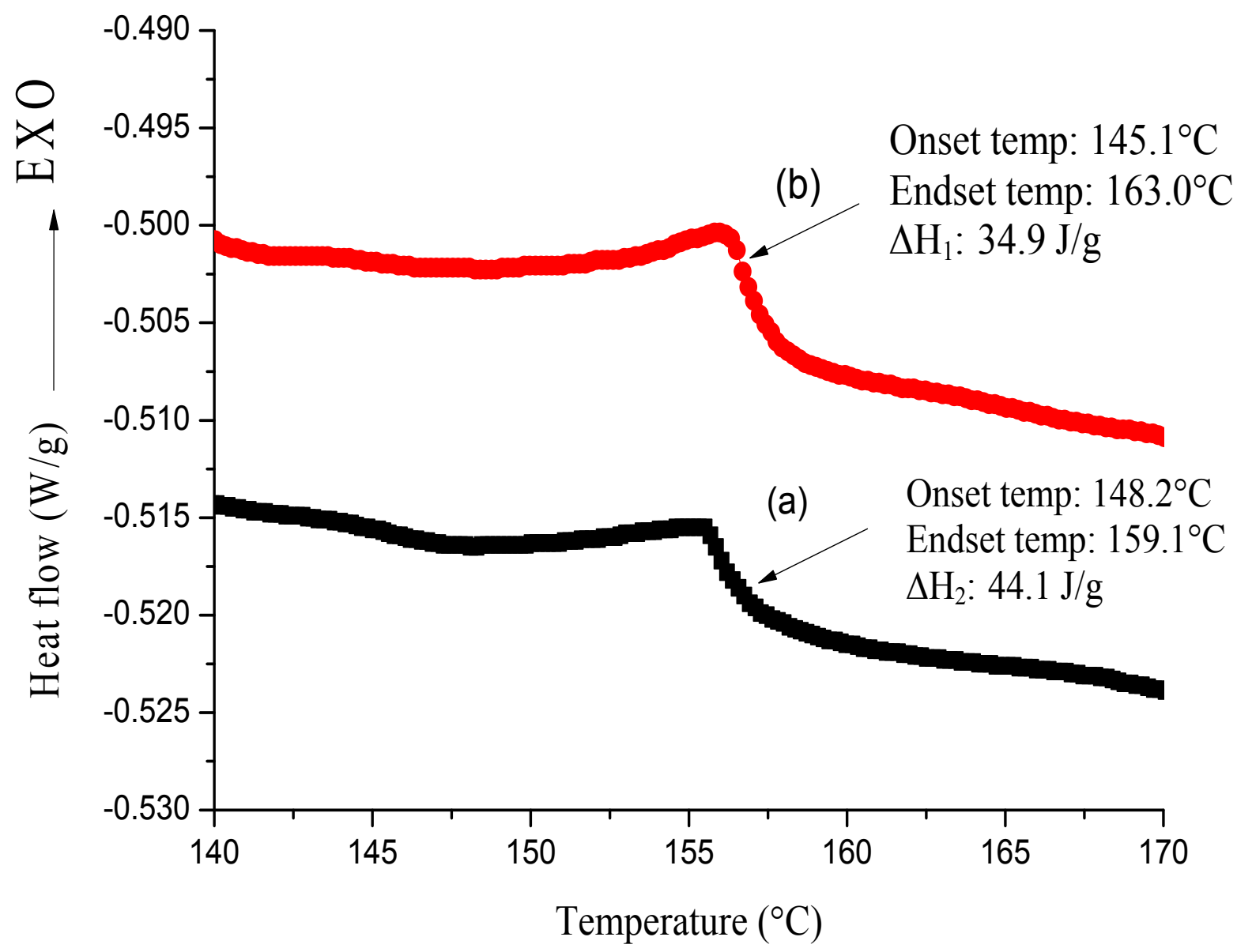

FIG. 8: DSC thermograms of (a) pure SR and (b) Cloisite $\mathrm{Na}^{+} / \mathrm{SR}$ nanocomposites. 


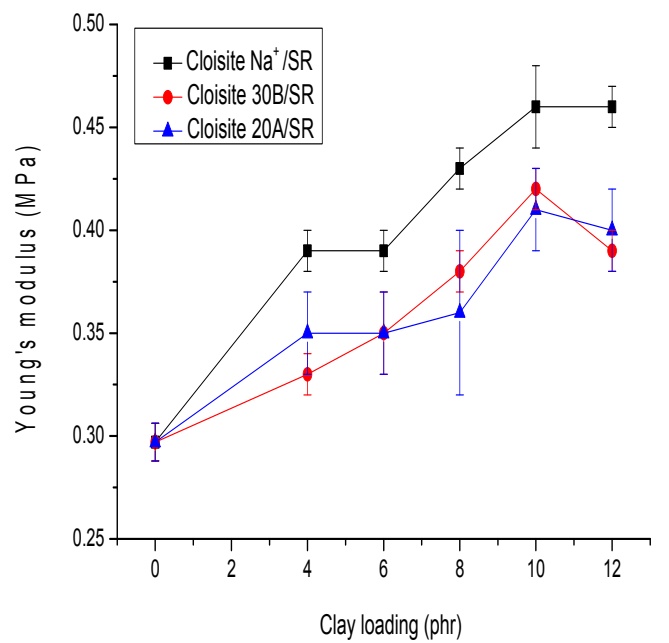

(a)

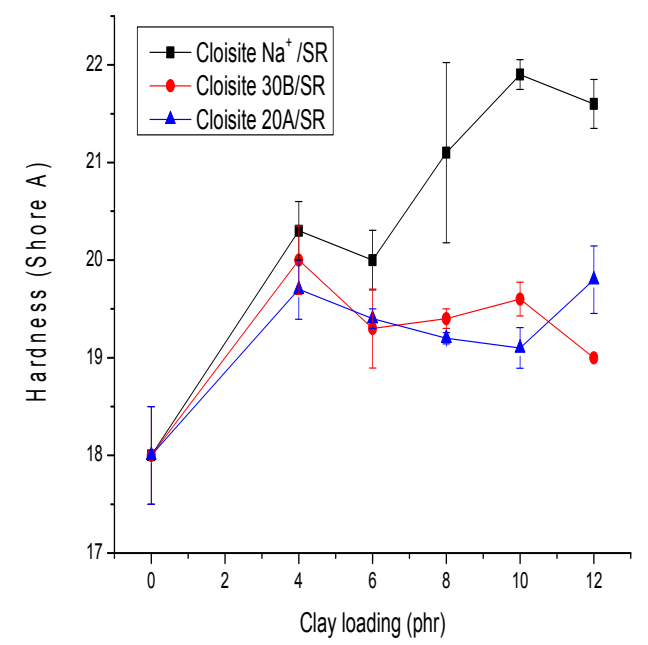

(c)

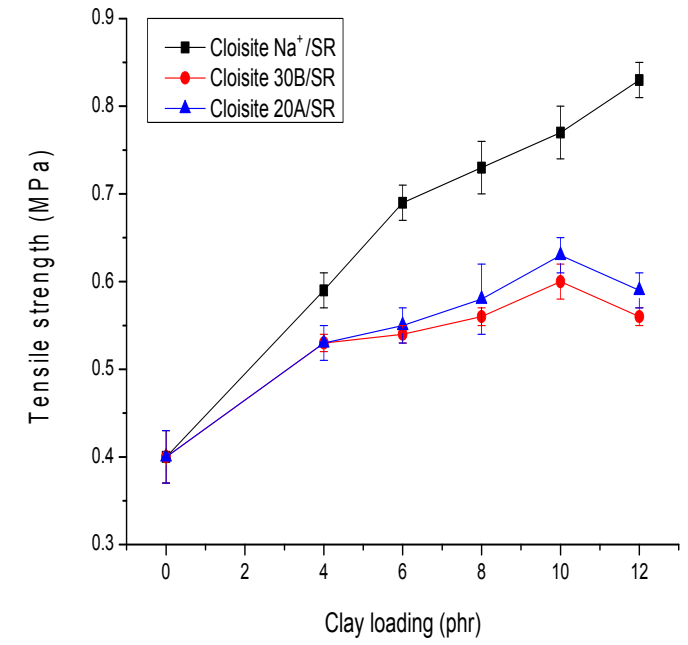

(b)

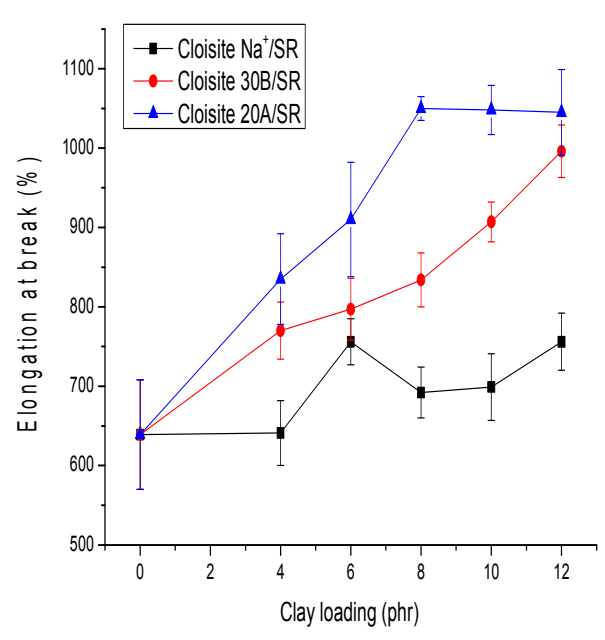

(d)

FIG 9: (a) Young's modulus, (b) tensile strength, (c) hardness, and (d) elongation at break of the clay/SR nanocomposites as a function of clay loading. Note data for the pure SR at 0 loading of the fillers. 


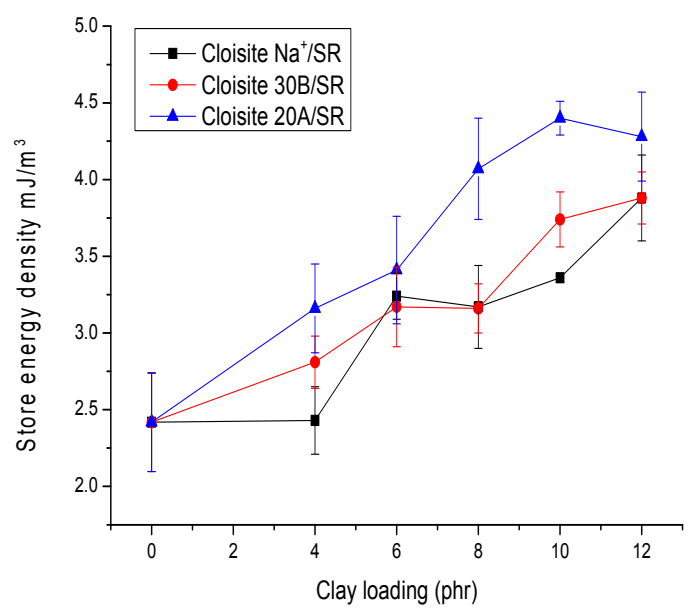

(e)

FIG 9: (e) Store energy density at break of the clay/SR nanocomposites as a function of clay loading. Note the data for the pure SR at 0 loading of the filler. 


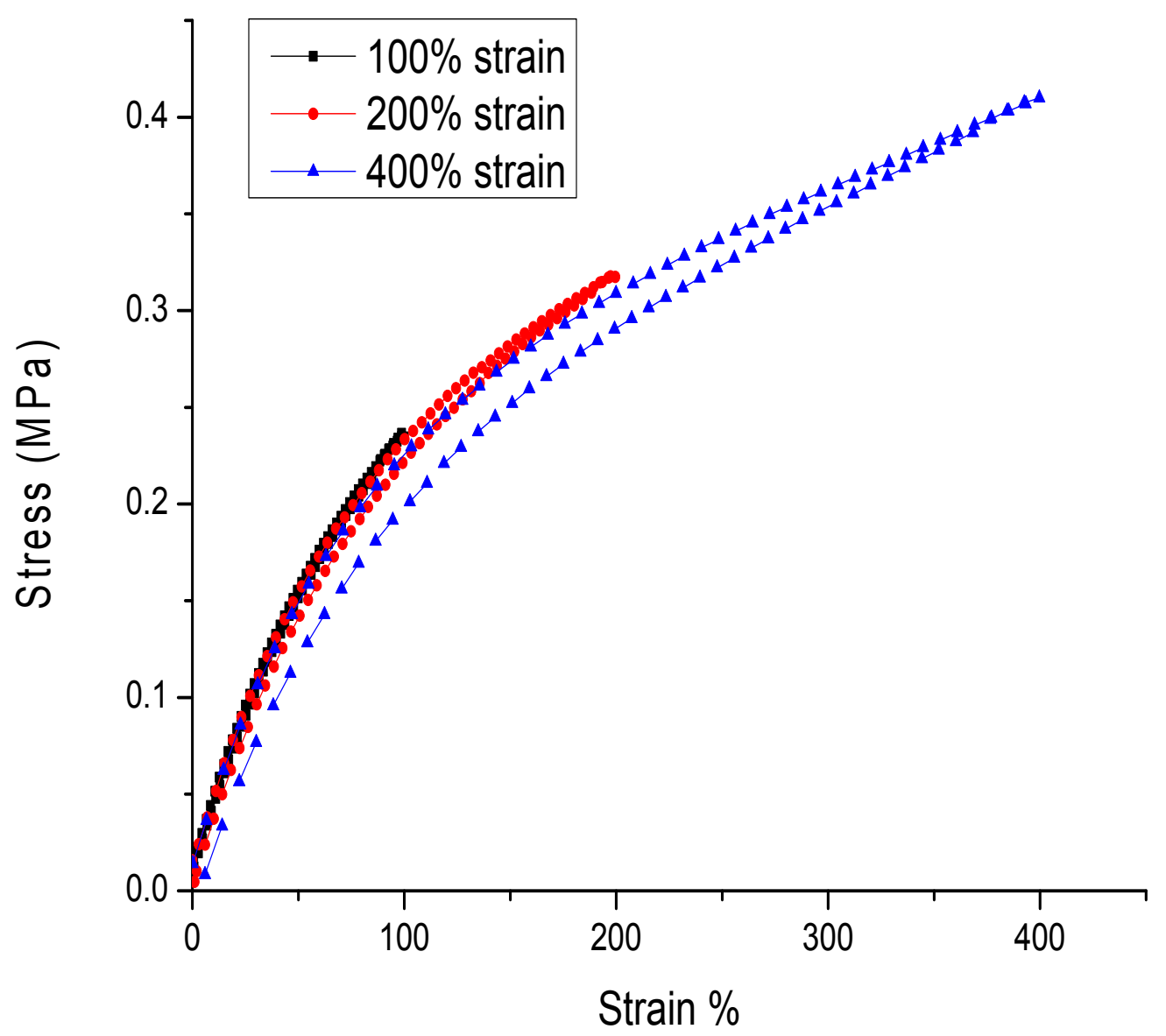

FIG 10: Typical hysteresis curves after the first stress versus strain cycle. Data for the pure SR at different strain amplitudes. 